Disponível em:

http://editora.unoesc.edu.br/index.php/race

Race, Joaçaba, v. 15, n. 2, p. 685-704, maio/ago. 2016

\title{
MOTIVAÇÕES PARA A EXPULSÃO DE CONTABILISTAS DO SERVIÇO PÚBLICO FEDERAL BRASILEIRO
}

\author{
Reasons for expulsion of accountants of Brazilian federal public service
}

Henrique Portulhak

E-mail: henrique.portulhak@ufpr.br

Mestre e doutorando em Contabilidade pela Universidade Federal do Paraná; Professor Assistente do Departamento de Contabilidade na Universidade Federal do Paraná. Endereço para contato: Av. Prefeito Lothário Meissner, 632, Jardim Botânico, 80210-170, Curitiba, Paraná, Brasil.

Renan Felipe Barilli

E-mail: renan.barilli@hotmail.com Graduado em Educação Física pelo Centro Universitário Autônomo do Brasil; pós-doutorando em Metodologia do Ensino da Matemática pela Faculdade de Pinhais.

Artigo recebido em 07 de março de 2016. Aceito em 25 de abril de 2016. 


\section{Resumo}

A corrupção no Brasil é considerada sistêmica, um problema grave e estrutural da sociedade e do sistema político, que enfraquece a moral pública e a legitimidade governamental. Um dos profissionais que possui como incumbência pautar suas ações com base em condutas éticas, podendo contribuir com a diminuição da corrupção no Estado é o contabilista. Contudo, tal profissional também pode estar envolvido em situações de corrupção. Dessa forma, a investigação verificou quais motivos levaram contabilistas à expulsão do serviço público federal brasileiro. Dados secundários foram obtidos por meio do Portal da Transparência do Governo Federal, compreendendo as punições ocorridas entre janeiro de 2003 e fevereiro de 2016, entre os quais foram destacados o fundamento legal que embasou a expulsão, UF e região de lotação, cargo efetivo, eventual cargo ou função de confiança, ano de publicação da portaria de punição, tipo de punição e gênero. Os resultados revelaram que as principais motivações para a expulsão de contabilistas do serviço público federal brasileiro, especialmente por meio de demissões, envolvem práticas de valimento, improbidade administrativa e lesão aos cofres públicos, englobando, principalmente, técnicos em contabilidade, profissionais lotados na região Norte e no Distrito Federal, servidores do sexo masculino e sem cargo ou função de confiança, verificando-se um aumento nas expulsões a partir de 2011. Espera-se que tais resultados subsidiem ações de órgãos representativos a fim de conscientizar os contabilistas presentes no setor público com o intuito de mitigar a ocorrência de atos ilícitos provocados por estes no exercício de sua função.

Palavras-chave: Profissional contábil. Serviço público. Ética profissional. Corrupção.

\section{Abstract}

Corruption in Brazil is considered systemic, grave and a structural problem of society and the political system that undermines public morality and government legitimacy. One of the professionals who have the incumbency to base their actions on the ethical conduct, and may contribute to the reduction of corruption in the public service, is the accountant. However, this professional may also be involved in corruption. Thus, the investigation found the motivations of expulsions of accountants in the Brazilian federal public service. Secondary data were obtained through the Transparency Portal of the Brazilian Federal Government, including punishments occurred between January 2003 and February 2016, among which were highlighted the legal foundation that based expulsion, geographic area, effective position, position of trust, year of publication of the decree of punishment, kind of punishment and gender. Results showed that the main reasons for expulsion accountants Brazilian federal public service, especially through layoffs involve to avail himself of the position, improper conduct and injury to the public coffers, comprising mainly technical in accounting, professionals in the North Region and in the Federal District, male servers and without reliable function, verifying an increase in expulsions from the year 2011. It is expected that these results subsidize actions of representative 
bodies in order to educate accountants present in the public sector with the order to mitigate the occurrence of unlawful acts caused by them in the exercise of its function.

Keywords: Accounting professional. Public service. Professional ethics. Corruption.

\section{INTRODUÇÃO}

De acordo com a organização Transparência Internacional em seu ranking de corrupção, que tomou como base a avaliação do setor público de 175 países e territórios no ano 2014, o Brasil ocupa a 69ª posição (sendo o primeiro colocado como o país com menor corrupção no setor público), com escore de 43 pontos de um total de 100, sendo este o escore médio mundial e estando abaixo da média dos escores dos países do Continente Americano (45 pontos) e dos países do G20 (54 pontos) (TRANSPARENCY INTERNATIONAL, 2014).

Corroborando essa percepção, não é raro observar em diversos meios de comunicação brasileiros notícias relacionadas a escândalos de corrupção no País ligadas a entidades pertencentes ao Poder Público. Muitos casos notórios de corrupção no serviço público ocorreram nas últimas décadas, como destaca a Controladoria-Geral da União (CGU): Operação Navalha, Máfia dos Sanguessugas, Caso Furnas, Máfia dos Transportes e Fraude em Licitações da Saúde Pública do Rio de Janeiro. Ainda, destacam-se nesse período outros casos emblemáticos, como os casos dos Anões do Orçamento, do Mensalão e do Petrolão (BASILIO, 2015).

De acordo com Pereira (2002), a corrupção no Brasil é considerada sistêmica, um problema grave e estrutural da sociedade e do sistema político, um fenômeno que enfraquece o regime democrático, a confiança no Estado, a moral pública e a legitimidade governamental. Tais ações podem envolver agentes públicos, considerando-se que, historicamente, o funcionalismo de carreira apresenta problemas estruturais referentes à questão ética, com a ausência de normas e orientações específicas a respeito desse tema (CARNEIRO, 1998). Em consequência, demissões e cassações de aposentadoria ocorrem em órgãos públicos brasileiros. Como destacou a CGU, em 2015 ocorreram 541 expulsões de servidores por práticas ilícitas no âmbito da administração pública federal; 61\% dos casos possui ligação com corrupção (CONTROLADORIA GERAL DA UNIÃO, 2016a).

Nesse contexto, um dos profissionais que possui como incumbência fundamentar suas ações em procedimentos éticos e que possui capacidade de colaborar com o desenvolvimento da eficiência e da diminuição da corrupção no Estado é o contabilista. Por formação, o contabilista busca ser elemento de referência ética e de 
influência positiva na sociedade (KRAEMER, 2001). Ainda, como a contabilidade possui a capacidade de influenciar as decisões de diversos atores econômicos por meio da elaboração e transmissão de informações, torna-se relevante a preocupação com a conduta ética de seus profissionais (MORAES; SILVA; CARVALHO, 2010).

Entretanto, é possível que profissionais de contabilidade também estejam incluídos no conjunto de agentes públicos expulsos de seus cargos na Administração Pública, seja por corrupção seja por outras condutas em desacordo com o que se espera de um servidor público. Diante disso, torna-se relevante investigar quais motivos levaram esses profissionais a serem desligados de suas funções públicas. Com isso, na presente investigação buscou-se responder à seguinte questão: quais as motivações das expulsões de contabilistas do serviço público federal?

Dessa forma, nessa pesquisa o objetivo foi verificar as motivações que culminaram no desligamento de profissionais de contabilidade, como contadores e técnicos de contabilidade, das entidades pertencentes à Administração Pública Federal. Em específico, com essa investigação também se objetivou averiguar qual a participação dos atos de corrupção entre as motivações que provocaram a expulsão desses profissionais nesse âmbito, além de examinar relações entre as expulsões e o cargo, função de confiança, região, gênero e tipo de punição.

Diante dessa contextualização, justifica-se a realização deste estudo, considerando-se o posicionamento brasileiro no ranking de corrupção no serviço público (TRANSPARENCY INTERNATIONAL, 2014), a ocorrência de diversos escândalos de corrupção em entidades componentes da Administração Pública Federal (BASILIO, 2015), além da crescente preocupação da população brasileira a respeito desse tema, figurando entre as suas principais inquietações o lado da saúde (AVALIAÇÃO..., 2015). Ademais, sob um ponto de vista teórico, tal investigação faz-se relevante em razão da inexistência de publicações relacionadas ao tema e com enfoque aos profissionais em contabilidade do setor público brasileiro.

\section{REFERENCIAL TEÓRICO}

\section{1 ÉTICA DO PROFISSIONAL CONTÁBIL}

De acordo com Ward, Ward e Deck (1993), o entendimento comum existente sobre a ética - como um confronto entre o que é certo e errado ou entre o que é bom e ruim - pode ser considerado simplista. Para os autores, a questão ética envolve um processo complexo sobre escolhas que devem ser feitas em determinada situação de 
conflito, o que envolve o balanceamento entre interesses individuais e coletivos, além de elementos individuais (experiência e aprendizado) e fatores contextuais.

Nesse contexto, que abrange contínuas mudanças no ambiente legal, social, político e econômico, faz-se importante a existência de padrões e códigos de ética e de conduta para classes profissionais, para que seus membros possuam uma referência ao encararem dilemas éticos no exercício de sua atividade (WARD; WARD; DECK, 1993).

Como cita Alves (2005), a contabilidade é subordinada a um conjunto de regras e normas, sendo uma delas o código de ética da profissão, o qual tem como objetivo delimitar e embasar o comportamento que se espera dos contabilistas no exercício da função. Para Ward, Ward e Deck (1993), um código profissional ajuda ao demonstrar para o público que os membros de uma profissão são competentes, íntegros e que buscam manter e reforçar padrões de procedimento mais rigorosos do que é exigido por lei. De acordo com McCarthy (1997), a existência de um código de ética profissional, como existe nos Estados Unidos para os contadores, busca a apresentação por determinada classe profissional de uma imagem de maior confiança e credibilidade à sociedade.

No Brasil, a implantação do Código de Ética do Profissional Contábil ocorreu a partir do Decreto-Lei n. 9.295/1946, o qual sustenta que cabe ao sistema composto pelo Conselho Federal de Contabilidade e pelos Conselhos Regionais de Contabilidade a responsabilidade legal de habilitar, fiscalizar e punir as infrações vinculadas aos profissionais que compõem a classe contábil (ALVES, 2005).

O Conselho Federal de Contabilidade determina que o profissional contábil, no exercício de sua função, deve seguir o Código de Ética Profissional, disposto na Resolução CFC n. 803/1996. De acordo com o Artigo $1^{\circ}$ desse código, ele “[...] tem por objetivo fixar a forma pela qual se devem conduzir os Profissionais da Contabilidade, quando no exercício profissional e nos assuntos relacionados à profissão e à classe.” (CONSELHO FEDERAL DE CONTABILIDADE, 1996). Quanto aos deveres do profissional contábil, o inciso I do Artigo $2^{\circ}$ enuncia: "I - Exercer a profissão com zelo, diligência e honestidade, observada a legislação vigente e resguardados os interesses de seus clientes e/ou empregadores, sem prejuízo da dignidade e independência profissionais.” (CONSELHO FEDERAL DE CONTABILIDADE, 1996, p. 18).

A importância da existência de um código de ética para o profissional contábil pode ser observada ao se ressaltarem as considerações de Vieira (2003), que afirma que o contador se torna a cada dia mais importante por conta da crescente valorização de seu papel enquanto profissional, considerando-se sua ação nas empresas e na sociedade em geral. De acordo com o autor, a sociedade tem observado que a con- 
tabilidade não se ocupa apenas em controlar e registrar ocorrências administrativas, fazer a escrituração de livros fiscais e em efetuar a geração de guias de recolhimento de tributos.

Tendo vivência empresarial, o profissional contábil é solicitado regularmente a opinar a respeito da situação da empresa e, até mesmo, quanto ao futuro dela, sendo indagado sobre qual caminho deve ser percorrido. Assim, o profissional contábil se torna peça fundamental para a sobrevivência e o desenvolvimento das empresas, gerando informações úteis para a tomada de decisões (VIEIRA, 2003).

Em complemento, Santana Junior, Pereira e Lopes (2008) afirmam que, em razão de um processo de globalização e internacionalização das transações empresariais, o que trouxe importantes modificações nos setores privados e público, seja com a desregulamentação do fluxo internacional de capitais, seja pelos avanços tecnológicos e científicos, ocorreram alterações nas relações entre empregador e empregado, exigindo-se evolução em sua capacidade intelectual e no aspecto ético.

Desta feita, como afirma Kraemer (2001), os profissionais contábeis são profissionais incumbidos de pautar sua trajetória na ética profissional, especialmente ao se considerar que sua atividade, gerando relatórios e demonstrativos, efetuando registros, bem como pela assinatura técnica de responsabilidade pelo serviço prestado, envolve a exposição de informações para diversos interessados nas atividades de seus clientes. Entretanto, deve-se ressaltar que a decisão final sobre como proceder em determinada situação fica a cargo do indivíduo (WARD; WARD; DECK, 1993).

Dessa forma, conforme Moraes, Silva e Carvalho (2010), denúncias de fraudes envolvendo os profissionais contábeis têm sido comuns, fazendo com que esses comportamentos prejudiquem a confiança do profissional contábil perante a sociedade. Finn, Chonko e Hunt (1988) especificam algumas atitudes antiéticas que podem se refletir na qualidade da informação reportada pelas empresas e na reputação dos profissionais contábeis: divulgação de lucros e condição financeira superavaliados, falsificação de documentos, práticas contábeis em desacordo com os princípios contábeis geralmente aceitos e divulgação de informações falsas.

Nesse contexto, Silva e Speroni (1998 apud VIEIRA, 2003, p. 57) lembram que “[...] a ética profissional tem como premissa maior o relacionamento do profissional com seus clientes e com outros profissionais, levando em conta valores como a dignidade humana, auto-realização e sociabilidade.” Como lembram Finn, Chonko e Hunt (1988), os conflitos éticos ocorrem no momento em que ocorre a interação entre indivíduos, sendo, nesse momento, seus papéis, responsabilidades e expectativas confrontados. Dessa forma, considerando-se tais afirmações sob a ótica da atuação do 
profissional contábil, deseja-se que tais valores se reflitam na qualidade do trabalho executado pelo profissional contábil, em especial na elaboração e divulgação de informações para os diversos stakeholders de uma organização.

Vale ressaltar que os fatores individuais e as influências sofridas interferem a tomada de decisão do profissional em ser ético ou não, considerando-se, especialmente, suas experiências profissionais e pessoais (FINN; CHONKO; HUNT, 1988; ALVES et al., 2007). Dessa forma, faz-se importante considerar o conjunto de normas e regras existentes em um contexto profissional específico, como o serviço público.

\section{2 ÉTICA NO SERVIÇO PÚBLICO BRASILEIRO}

No setor público brasileiro nota-se que a determinação de procedimentos éticos passa pela criação de um aparato fortemente normativo. Inicialmente, cita-se a Lei n. 8.112/1990, a qual dispõe sobre o regime jurídico dos servidores públicos civis da União, das autarquias e das fundações públicas federais.

Nessa Lei, destaca-se no seu Artigo 116, que compõe o Capítulo I (dos Deveres) do Título IV (do Regime Disciplinar), os seguintes elementos de conduta que devem ser considerados pelos servidores federais no exercício de sua função: atender com presteza, cumprir as ordens superiores exceto quando ilegais, observar as normas legais e manifestantes, ser leal a quem servir e exercer com zelo e dedicação as funções atribuídas ao cargo (BRASIL, 1990).

Em complemento, cita-se a Lei n. 8.429/1992, que dispõe sobre as sanções aplicáveis aos agentes públicos nos casos de enriquecimento ilícito no exercício de mandato, cargo, emprego ou função na administração pública direta, indireta ou fundacional e dá outras providências. Em seu Artigo $7^{\circ}$, apresenta-se que, caso haja um ato de improbidade promovido por servidor que cause lesão ao patrimônio público ou ocasione enriquecimento ilícito, a autoridade responsável encaminhará o caso para o Ministério Público, para que haja a indisponibilidade dos bens do indiciado, estendendo-se a responsabilização para sucessores no caso de existência de herança, como cita o Artigo $8^{\circ}$ da mesma Lei (BRASIL, 1992).

Entretanto, Carneiro (1998) afirma que, no contexto do serviço público, qualquer política de promoção da ética nesse ambiente deve enfocar, antes e com maior ênfase, medidas de cunho prático e ações efetivas, tanto de prevenção quanto de repressão, do que meramente a construção e manutenção exclusiva de peças jurídicas. De acordo com o autor, um dos fatores críticos para se determinar e se manter um patamar de desenvolvimento ético, em um país de grandes proporções no qual o aparato jurídico é 
rigoroso e centralizador, seria a clareza dos processos decisórios, o que infelizmente não é uma característica tradicional nesse ambiente, no qual se demonstra o mínimo possível de transparência e se proporciona o máximo de liberdade para deliberações.

Na mesma linha de raciocínio, Carneiro (1998) afirma, portanto, que o problema que envolve a conduta ética no serviço público brasileiro não é pertinente à falta de leis, mas à falta de aplicação e fiscalização das leis já existentes. Dessa forma, o autor reconhece que, em alguns casos, a edição de leis é inevitável, porém opina que a conduta ética do servidor poderia ser regulamentada diretamente pelo Poder Executivo, colocando, com isso, o foco em pontos mais urgentes e relevantes sobre a forma de acolher denúncias e apurar infrações.

\section{METODOLOGIA}

A presente investigação pode ser enquadrada como qualitativa em relação ao problema de pesquisa e descritivo-exploratória quanto à abordagem do problema (GIL, 2002; COOPER; SCHINDLER, 2003; RICHARDSON, 2008). Para isso, realizou-se uma análise documental, utilizando-se coleta de dados secundários. Os referidos dados, já tabulados, foram coletados por meio do sítio Portal da Transparência do Governo Federal, tomando como base os arquivos presentes na seção Cadastro de Expulsões da Administração Federal (CONTROLADORIA GERAL DA UNIÃO, 2016b). Nesse local, são disponibilizadas informações relativas a expulsões de servidores públicos federais, das quais foram extraídas as informações relacionadas a cargos que envolvam nomeadamente profissionais atuantes na área de contabilidade, a saber: contadores, técnicos em contabilidade e auxiliares de contabilidade.

Para a realização da análise, foram consideradas as informações disponibilizadas no Portal da Transparência do Governo Federal, seção Cadastro de Expulsões da Administração Federal, destacando-se as seguintes: UF de lotação; cargo efetivo; cargo ou função de confiança, se houver; data de publicação da portaria de punição; tipo de punição (demissão ou cassação de aposentadoria); gênero; fundamento legal. A obtenção de tais informações possibilitou a realização de inferências acerca do problema em tela, explorando-se de forma adicional possíveis características que estejam relacionadas a tais ocorrências, verificando-se, especialmente, a fundamentação legal que embasou as expulsões visando ao atendimento dos objetivos na pesquisa.

Quanto à dimensão de tempo, a investigação enquadra-se como longitudinal e, quanto ao escopo de estudo, como em amplitude (COOPER; SCHINDLER, 2003). Tal enquadramento, além de adequado às características da investigação, é viabilizado 
pela disponibilidade de informações por meio do Portal da Transparência do Governo Federal, com dados relativos à expulsão de servidores públicos federais ocorrida entre janeiro de 2003 e fevereiro de 2016.

\section{ANÁLISE DOS DADOS}

Na coleta de dados realizada no Portal da Transparência do Governo Federal no mês de março de 2016, realizou-se a seleção das ocorrências que envolveram antigos servidores os quais exerciam como cargos efetivos auxiliar de contabilidade, contador ou técnico em contabilidade. A busca retornou em 29 ocorrências entre 2003 e 2015 no âmbito da Administração Pública Federal.

\subsection{LOCAL DE LOTAÇÃO}

Em um primeiro momento, verificou-se nas ocorrências destacadas a lotação na qual o servidor expulso se encontrava no momento da punição. Quanto aos órgãos de lotação, destaca-se a existência de punições a sete servidores da Fundação Nacional de Saúde (Funasa), o que equivale a 24,1\% das punições a contabilistas, seis ocorrências em Universidades Federais (20,7\%) e quatro ocorrências no Ministério da Fazenda e na Fundação Nacional do Índio (Funai) (13,8\%), além de ocorrências na Agência Nacional do Petróleo (ANP), Marinha, Departamento Nacional de Obras Contra as Secas (DNOCS), institutos federais de educação, Instituto Nacional de Colonização e Reforma Agrária (INCRA), Instituto Nacional do Seguro Social (INSS), Ministério da Agricultura, Pecuária e Abastecimento, Ministério da Justiça, Ministério da Saúde e lotação de ex-território.

Quanto às Unidades da Federação (UFs) de lotação dos servidores expulsos, a distribuição geográfica pode ser representada de acordo com a Mapa 1. 
Mapa 1 - Distribuição geográfica das expulsões - 2003-2015

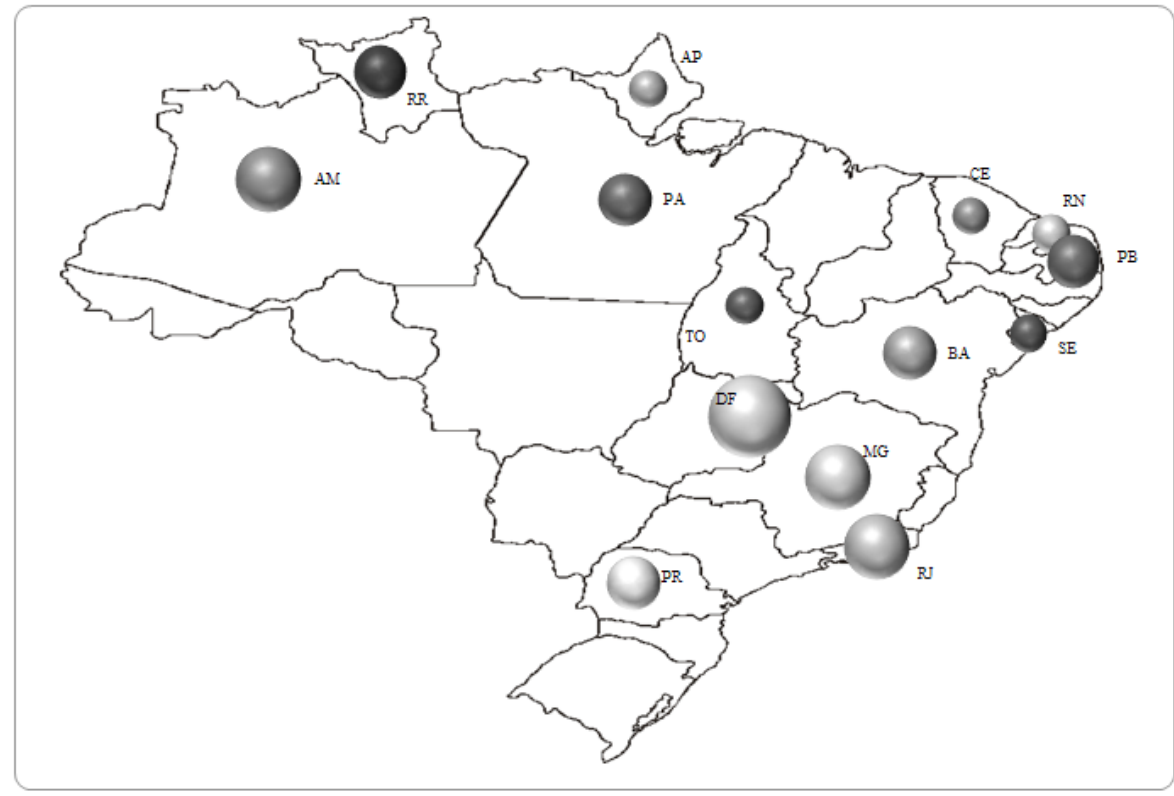

Fonte: adaptado de Santos (2012).

Conforme pode ser observado por meio do Mapa 1, observa-se que o Distrito Federal é a UF na qual consta a maior quantidade de contabilistas expulsos do serviço público federal (cinco ocorrências), o que presumivelmente ocorre pela concentração de servidores federais nessa localidade. Na sequência, destacam-se os Estados do Amazonas, Minas Gerais e Rio de Janeiro, com três ocorrências cada.

Quanto às regiões geográficas, observa-se uma maior ocorrência de expulsões de contabilistas na região Norte (nove punições), seguida pela região Nordeste (sete punições), Sudeste (seis punições), Centro-Oeste (cinco punições) e, por fim, a região Sul (duas punições).

\subsection{CARGO EFETIVO E CARGO OU FUNÇÃO DE CONFIANÇA}

Em relação ao cargo efetivo exercido pelos servidores federais punidos mapeados nessa investigação, a sua distribuição pode ser mais bem compreendida por meio do Gráfico 1. 


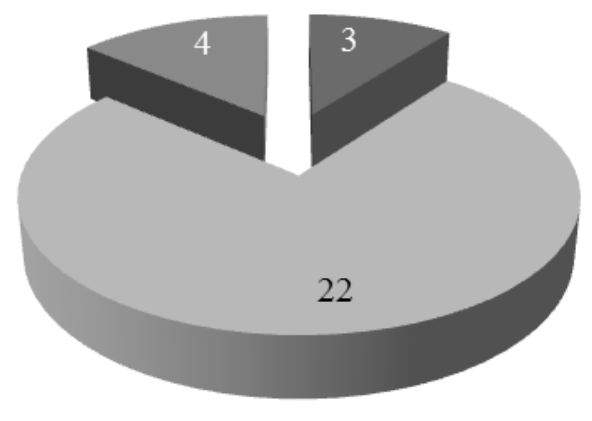

- Auxiliar de Contabilidade

- Técnico em Contabilidade

- Contador

Fonte: os autores.

Como se pode depreender do Gráfico 1, nota-se que, entre os cargos efetivos selecionados para essa investigação, a grande maioria das punições ocorreu contra técnicos em contabilidade (75,9\%), enquanto quatro punições ocorreram contra auxiliares de contabilidade (13,8\%) e três punições contra contadores (10,3\%).

Já sobre cargos e funções de confiança, observou-se que dois servidores punidos (6,9\%) exerciam cargo ou função de confiança no momento da publicação da portaria de punição, sendo um contador que exercia a função de chefe de serviço e um técnico em contabilidade que exercia a função de coordenador.

\subsection{DATA DE OCORRÊNCIA DA PUNIÇÃO}

Quanto à data de ocorrência da publicação da portaria de punição, optou-se por concentrar as ocorrências de acordo com o ano. A evolução das punições capturadas no Portal da Transparência do Governo Federal está representada no Gráfico 2. 
Gráfico 2 - Quantidade de expulsões por ano - 2003-2015

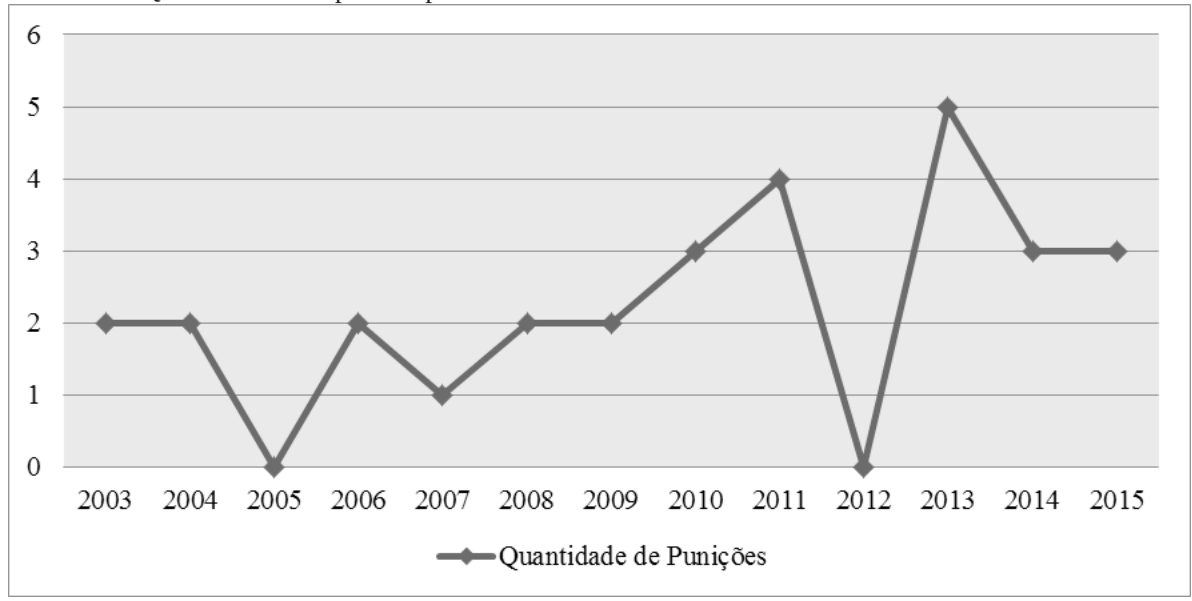

Fonte: os autores.

Conforme o exposto no Gráfico 2, é possível observar um aumento na ocorrência de punições a contabilistas no âmbito do serviço público federal a partir de 2010, chegando a um pico de cinco punições no ano 2013, apesar da inexistência de registros de punições no ano 2012. No ano mais recente (2015), observou-se a ocorrência de três punições, a mesma quantidade ocorrida no ano anterior (2014).

\subsection{TIPO DE PUNIÇÃO}

De acordo com as informações presentes no Portal da Transparência do Governo Federal, dois tipos de punição foram aplicados aos servidores mapeados nessa investigação: demissão e cassação de aposentadoria. Tais penalidades são previstas no Artigo 127 da Lei n. 8.112/1990, que dispõe sobre o regime jurídico único dos servidores federais (BRASIL, 1990).

Observa-se, de acordo com os dados coletados, que 25 dos 29 servidores punidos $(86,2 \%)$ sofreram demissão dos cargos que ocupavam no período de 2003 a 2015, enquanto três servidores (10,3\%) sofreram cassação de aposentadoria e um servidor federal sofreu tanto a demissão do cargo efetivo quanto a cassação de sua aposentadoria. 


\subsection{FUNDAMENTO LEGAL}

No que se refere ao fundamento legal, o qual exprime a motivação que levou contabilistas a serem expulsos do serviço público federal, notou-se, primeiramente, que as 29 expulsões mapeadas foram baseadas em 121 fundamentos legais, considerando-se que servidores podem ser enquadrados em mais de um fundamento legal para embasamento de sua punição.

Para sete servidores, foram considerados dois fundamentos legais, para cinco servidores, três fundamentos legais foram elencados e para outros cinco servidores, um fundamento legal foi considerado, entre outras distribuições. Destaca-se, ainda, o caso de um servidor ao qual, para sua expulsão, foram elencados 11 fundamentos legais.

Quanto aos fundamentos legais mais recorrentes, na Tabela 1 apresentam-os em ordem de ocorrência.

Tabela 1 - Fundamentos Legais das Expulsões - 2003-2015

\begin{tabular}{cccccccc}
\hline Lei & Artigo & Inciso & Quant. & Lei & Artigo & Inciso & Quant. \\
8112 & 117 & IX & 21 & 8112 & 116 & VII & 1 \\
8112 & 132 & IV & 20 & 8112 & 116 & VIII & 1 \\
8112 & 132 & X & 12 & 8112 & 116 & XII & 1 \\
8112 & 116 & III & 7 & 8112 & 117 & XI & 1 \\
8112 & 132 & XIII & 7 & 8112 & 117 & XII & 1 \\
8112 & 116 & I & 6 & 8112 & 117 & XVIII & 1 \\
8112 & 116 & II & 6 & 8112 & 127 & IV & 1 \\
8112 & 116 & IX & 4 & 8112 & 132 & Não inf. & 1 \\
8112 & 117 & XV & 4 & 8112 & 132 & I & 1 \\
8112 & 116 & IV & 3 & 8112 & 132 & II & 1 \\
8112 & 132 & VIII & 3 & 8112 & 134 & Caput & 1 \\
8112 & 132 & XIII & 3 & 8429 & 10 & Caput & 1 \\
8429 & 11 & Caput & 3 & 8429 & 10 & II & 1 \\
8112 & 117 & VI & 2 & 8429 & 10 & III & 1 \\
8112 & 117 & XVI & 2 & 8429 & 11 & I & 1 \\
8429 & 10 & I & 2 & 8429 & 9 & I & 1 \\
\hline
\end{tabular}

Fonte: os autores.

Observa-se, de acordo com os dados da Tabela 1, que as leis que fundamentam as expulsões de contabilistas do serviço público federal são a n. 8.112/1990 e a 
n. 8.429/1992. Destaca-se na Tabela 1 como principal fundamento legal o Inciso IX do Artigo 117 da Lei n. 8.112/1990, com 21 ocorrências, que enuncia: "Valer-se do cargo para lograr proveito pessoal ou de outrem, em detrimento da dignidade da função pública.” Como explica Oliveira e Filho (2013), a chamada prática do valimento:

[...] implica em atos ou omissão de cunho deliberadamente dolosos, no sentido de praticar algo vedado pela legislação ou pela moralidade administrativa, podendo gerar proveito pessoal ou de terceiros, e sempre causando o detrimento da dignidade do múnus público.

Na sequência, com 20 ocorrências, a Tabela 1 destaca entre os principais fundamentos legais o Inciso IV do Artigo 132 da Lei n. 8.112/1990, que enuncia "Improbidade administrativa”. Como afirma Tolosa Filho (2003, p. 42):

Improbidade administrativa é a conduta antiética do agente do Poder Público, na condução da "coisa pública”, desviando-se dos princípios de legalidade, impessoalidade, moralidade, publicidade e eficiência, independentemente de causar lesão ao erário ou de se enriquecer ilicitamente.

Outro fundamento legal que se destaca entre aqueles que justificaram a expulsão de contabilistas do serviço público federal é o Inciso X do Artigo 132 da Lei n. 8.112/1990, que enuncia “Lesão aos cofres públicos e dilapidação do patrimônio nacional”, com 12 ocorrências.

Também se deve destacar o Inciso III do Artigo 116 da Lei n. 8.112/1990, com sete ocorrências, que enuncia “Observar as normas legais e regulamentares”, e o Inciso XIII do Artigo 132 da referida Lei, também com sete ocorrências, que enuncia “Transgressão dos incisos IX a XVI do art. 117”. Quanto a este último item, destaca-se que os Incisos IX a XVI do Artigo 117 da Lei n. 8.112/1990 mencionam, respectivamente, as seguintes proibições: "Valer-se do cargo para lograr proveito pessoal ou de outrem, em detrimento da dignidade da função pública” e "Utilizar pessoal ou recursos materiais da repartição em serviços ou atividades particulares”.

Por fim, menciona-se entre os principais motivadores das expulsões de contabilistas do serviço público federal os seguintes fundamentos legais, cada um com seis ocorrências: os Incisos I e II do Artigo 116 da Lei n. 8.112/1990, que enunciam, respectivamente, "Exercer com zelo e dedicação as atribuições do cargo" e "Ser leal às instituições a que servir”. 


\subsection{GÊNERO}

Também foi identificado, tomando como base os dados fornecidos pelo Portal da Transparência do Governo Federal, o gênero dos servidores federais que sofreram demissão ou cassação de aposentadoria entre 2003 e 2015 e que ocupavam cargos efetivos identificados com áreas de atuação de contabilistas.

De acordo com a análise empreendida, constatou-se que 79,3\% dos servidores federais punidos pertencem ao sexo masculino (23 servidores), enquanto 20,7\% pertencem ao sexo feminino (6 servidoras).

\section{CONCLUSÃO}

Na presente investigação teve-se por objetivo verificar os principais motivos que levaram contabilistas a serem expulsos do serviço público federal brasileiro. Para isso, foram extraídos e analisados dados presentes no Cadastro de Expulsões da Administração Federal, por sua vez, presente no Portal da Transparência do Governo Federal, de expulsões de servidores em cargos efetivos de auxiliar de contabilidade, técnico em contabilidade e contador ocorridas entre janeiro de 2003 e fevereiro de 2016.

Com base nas 29 expulsões de contabilistas identificadas na base de dados mencionada (especialmente por meio de demissões), algumas conclusões podem ser tecidas. Em primeiro lugar, retomando a questão de pesquisa, notou-se que em 72,4\% dos casos infringiu-se o Inciso IX do Artigo 117 da Lei n. 8.112/1990 (21 ocorrências), que enuncia: "Valer-se do cargo para lograr proveito pessoal ou de outrem, em detrimento da dignidade da função pública.” Na sequência, em 69\% dos casos, infringiu-se o Inciso IV do Artigo 132 da referida Lei, que enuncia "Improbidade administrativa” (20 ocorrências).

Também se destacam a ocorrência de "Lesão aos cofres públicos e dilapidação do patrimônio nacional” (12 ocorrências, 41,4\%), “Observar as normas legais e regulamentares” (7 ocorrências, 24,1\%) e “Transgressão dos incisos IX a XVI do art. 117”, que, por sua vez, citam: "Valer-se do cargo para lograr proveito pessoal ou de outrem, em detrimento da dignidade da função pública” e "Utilizar pessoal ou recursos materiais da repartição em serviços ou atividades particulares” (7 ocorrências, 24,1\%).

Conhecer a respeito dos principais fundamentos legais que envolvem as expulsões de contabilistas do serviço público federal é importante a partir do momento em que se considera a existência de inúmeros escândalos de corrupção em órgãos da Administração Pública Federal e a incumbência ética que envolve o exercício pro- 
fissional do contabilista em todas as suas áreas de atuação. Como apresentado no referencial teórico deste artigo, a importância crescente do papel do profissional contábil nas empresas e na sociedade demanda a manutenção de uma conduta ética que fortaleça a imagem da profissão na sociedade, sendo meios de orientação desses profissionais o Código de Ética do Profissional Contábil e, no caso de contabilistas que atuam no serviço público federal, as normas que tratam especificamente da conduta ética do servidor público.

Dessa forma, tais elementos podem direcionar campanhas de órgãos representativos de contabilistas presentes no serviço público, visando conscientizar e instruir esses profissionais para evitarem condutas que envolvam atos ilícitos e que possam resultar em expulsões de servidores e máculas sobre a atividade do profissional contábil, especialmente ao verificar um maior número de ocorrências a partir de 2011. Nesse contexto, faz-se relevante retomar as considerações de Carneiro (1998): a questão da ética do servidor público brasileiro, na qual se incluem os contabilistas, não se resolve apenas com a edição de novas peças jurídicas, as quais já são bastante numerosas, mas com a promoção de iniciativas de prevenção e de punição a atitudes consideradas eticamente inadequadas.

Outros elementos colhidos e analisados nessa investigação podem subsidiar tais ações, mas de forma mais específica. Quanto à região geográfica, na pesquisa destacou-se a maior ocorrência de expulsões na Região Norte e, quanto à UF de lotação, destaca-se uma maior ocorrência no Distrito Federal. Em relação ao cargo de exercício, destaca-se a predominância de punições a técnicos em contabilidade. Já no que se refere ao gênero, observa-se uma maior ocorrência com servidores do sexo masculino.

Com a realização dessa investigação, também são sugeridas novas pesquisas que possam ajudar a compor o quadro de expulsões de profissionais contábeis do serviço público. Nesse contexto, podem ser consideradas investigações em outros âmbitos, como estados e municípios, bem como envolvendo outros cargos efetivos, além de contadores, técnicos em contabilidade e auxiliares de contabilidade, o que pode suprir limitações dessa investigação ao não possibilitar a verificação de contabilistas que, porventura, estejam em outros cargos efetivos, como auditores fiscais e analistas de planejamento e gestão. Já para a prática, a realização de ações de prevenção por entidades representativas da classe contábil com contabilistas presentes no serviço público pode ser subsidiada pelos resultados apresentados neste artigo, aumentando as possibilidades de reflexos positivos para toda a classe contábil brasileira. 


\section{REFERÊNCIAS}

ALVES, F. J. dos S. A adesão do contabilista ao código de ética da sua profissão: um estudo empírico sobre percepções. 2005. Tese (Doutorado em Ciências Contábeis)-Universidade de São Paulo, São Paulo, 2005. Disponível em: <http://www. teses.usp.br/teses/disponiveis/12/12136/tde-23012006-103126/>. Acesso em: 05 out. 2015.

ALVES, F. J. dos S. et al. Um estudo empírico sobre a importância do código de ética profissional para o contabilista. Revista Contabilidade \& Finanças, p. 58-68, 2007. Edição Especial.

AVALIAÇÃO da presidente Dilma Rousseff. Avaliação do Congresso Nacional, expectativas econômicas, operação Lava Jato, Petrobrás. Datafolha - Instituto de Pesquisas, 2015. Disponível em: <http://datafolha.folha.uol.com.br/opiniaopublica/2015/04/1615892-reprovacao-a-dilma-para-de-subir-mas-maioria-ainda-rejeita-seu-governo.shtml>. Acesso em: 04 mar. 2016.

BASILIO, A. Os maiores escândalos de corrupção do Brasil. Época Negócios, 2015. Disponível em: <http://epocanegocios.globo.com/Informacao/Dilemas/noticia/2015/03/os-maiores-escandalos-de-corrupcao-do-brasil.html>. Acesso em: 03 mar. 2016.

BRASIL. Lei n. 8.112, de 11 de dezembro de 1990. Dispõe sobre o regime jurídico dos servidores públicos civis da União, das autarquias e das fundações públicas federais. Diário Oficial da União, Brasília, DF, 19 abr. 1991. Disponível em: <http:// www.planalto.gov.br/ccivil_03/leis/18112cons.htm>. Acesso em: 04 mar. 2016.

BRASIL. Lei n. 8.429, de 02 de junho de 1992. Dispõe sobre as sanções aplicáveis aos agentes públicos nos casos de enriquecimento ilícito no exercício de mandato, cargo, emprego ou função na administração pública direta, indireta ou fundacional e dá outras providências. Diário Oficial da União, Brasília, DF, 03 jun. 1992. Disponível em: <http://www.planalto.gov.br/ccivil_03/leis/18429.htm>. Acesso em: 04 mar. 2016.

CARNEIRO, J. G. P. O aprimoramento da conduta ética no serviço público federal. Revista do Serviço Público, v. 49, n. 3, p. 120-133, 1998.

\section{CONSELHO FEDERAL DE CONTABILIDADE. Código de Ética Profissional} do Contador. Resolução CFC n. 803/96. 1996. Disponível em: <www.cfc.org.br/ sisweb/sre/docs/RES_803.doc>. Acesso em: 04 mar. 2016. 
CONTROLADORIA-GERAL DA UNIÃO. Governo Federal expulsa 541 servidores em 2015 por atividades contrárias à lei. Disponível em: <http://www.cgu. gov.br/noticias/2016/01/governo-federal-expulsa-541-servidores-em-2015-por-atividades-contrarias-a-lei>. Acesso em: 07 mar. 2016a.

\section{CONTROLADORIA-GERAL DA UNIÃO. Portal da Transparência do Governo}

Federal. Disponível em: <http://www.portaltransparencia.gov.br>. Acesso em: 05 mar. $2016 b$.

COOPER, D. R.; SCHINDLER, P. S. Métodos de pesquisa em administração. 7. ed. Porto Alegre: Bookman, 2003.

FINN, D. W.; CHONKO, L. B.; HUNT, S. D. Ethical problems in public accounting: the view from the top. Journal of Business Ethics, v. 7, i. 8, p. 605-615, 1988.

GIL, A. C. Como elaborar projetos de pesquisa. 4. ed. São Paulo: Atlas, 2002.

KRAEMER, M. E. P. Ética, sigilo e o profissional contábil. Contabilidade Vista \& Revista, v. 12, n. 2, p. 33-47, 2001.

MCCARTHY, I. N. Professional ethics code conflict situations: Ethical and value orientation of collegiate accounting students. The Business Ethics Journey, Netherlands: Universities to the Marketplace, p. 257-263, Spring 1997.

MORAES, M. C. C. de; SILVA, A. M. C. da; CARVALHO, F. A. A. de. O comportamento dos futuros contabilistas perante diferentes dilemas éticos. Pensar Contábil, v. 12, n. 48, p. 22-30, 2010.

OLIVEIRA FILHO, V. A. R. de. Demissão do servidor público pela prática de valimento e o dolo como elemento indispensável ao seu enquadramento. Conteúdo Jurídico, 2013. Disponível em: <http://www.conteudojuridico.com.br/?artigos\&ver=2.45711\&seo=1>. Acesso em: 07 mar. 2016.

PEREIRA, J. M. Reforma do Estado e transparência: estratégias de controle da corrupção no Brasil. In: CONGRESO INTERNACIONAL DEL CLAD SOBRE LA REFORMA DEL ESTADO Y DE LA ADMINISTRACIÓN PÚBLICA, 7., 2002, Lisboa, Anais... Lisboa: CLAD, 2002. Disponível em: <http://repositorio.unb.br/bitstream/10482/940/4/ ARTIGO_ReformaEstadoTransparencia.pd>. Acesso em: 03 mar. 2016.

RICHARDSON, R. J. Pesquisa social: métodos e técnicas. 3. ed. São Paulo: Atlas, 2008. 
SANTANA JUNIOR, J. J. B. de; PEREIRA, D. M. V. G.; LOPES, J. E. de G. Análise das habilidades cognitivas requeridas dos candidatos ao cargo de contador na administração pública federal, utilizando-se indicadores fundamentados na visão da taxonomia de Bloom. Revista Contabilidade \& Finanças, v. 19, n. 46, p. 108-121, 2008.

SANTOS, A. O. Como criar um gráfico com mapa do Brasil no Excel. Guia do Excel. 2012. Disponível em: <http://guiadoexcel.com.br/grafico-mapa-do-brasil>. Acesso em: 07 mar. 2016.

TOLOSA FILHO, B. Comentários à lei de improbidade administrativa: de acordo com a Medida Provisória n. 1.088 e a lei de responsabilidade fiscal. Rio de Janeiro: Forense, 2003.

TRANSPARENCY INTERNATIONAL. Corruption Perceptions Index 2014. 2014. Disponível em: <http://www.transparency.org/cpi2014/results>. Acesso em: 03 mar. 2016.

VIEIRA, M. G. A influência da ética no perfil do profissional contábil. Revista do Conselho Regional de Contabilidade de Santa Catarina, v. 6, p. 55-60, 2003.

WARD, S. P.; WARD, D. R.; DECK, A. B. Certified public accountants: ethical perception skills and attitudes on ethics education. Journal of Business Ethics, v. 12, i. 8, p. 601-610, 1993.

Como citar este artigo:

ABNT:

PORTULHAK, Henrique; BARILLI, Renan Felipe. Motivação para a expulsão de contabilistas do serviço público Federal Brasileiro. RACE, Revista de Administração, Contabilidade e Economia, Joaçaba: Ed. Unoesc, v. 15, n. 2, p. 685-704, maio/ago. 2016. Disponível em: <http://editora.unoesc.edu.br/index.php/race>. Acesso em: dia/mês/ano..

APA:

Portulhak, H., \& Barilli, R. F. (2016). Motivação para a expulsão de contabilistas do serviço público Federal Brasileiro. RACE, Revista de Administração, Contabilidade e Economia, 15(2), 685-704. Recuperado de http://editora.unoesc.edu.br/index.php/ race 
